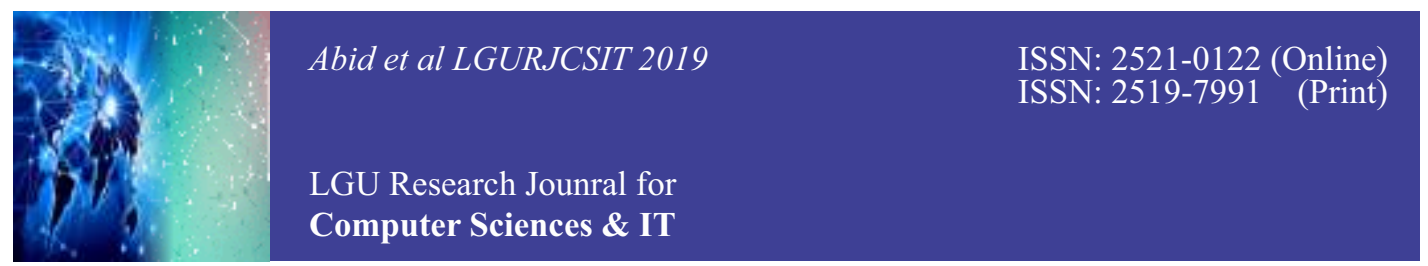

Vol. 3 Issue 2, April - June 2019

\title{
Cognitive Radio and Dynamic Spectrum Access Using Fuzzy Logic
}

${ }^{1}$ Rabia Khan, ${ }^{2}$ Muhammad Bilal Butt, ${ }^{3}$ Sabreena Nawaz

${ }^{1}$ Department of Computer Science, Lahore Garrison University, Lahore.

${ }^{2}$ Department of Computer Science, Govt. MAO College, Lahore.

${ }^{3}$ Department of Computer Science, Lahore Garrison University, Lahore.

\section{Abstract:}

Cognitive Radio is artificially intelligent radio. This research paper work presents an application of Cognitive Radio and Dynamic Spectrum Access with the help of fuzzy logic considering the inputs: radio and satellite frequency and outputs: adjust power and modulation. This research paper shows the real approach of comparing the simulation and design algorithm result and its successful use.

Keywords: $\quad$ Software Defined Radio, Cognitive Radio, Spectrum Sensing, Dynamic Spectrum Access, Fuzzy Logic.

\section{INTRODUCTION}

Unlike wired network, the world of wireless network has limited the amount of links to be distributed among wireless service users. As a result, regulation of bandwidth spectrum requires radical redeem to allow optimal, creative and efficient use of precious resource airwaves.

Today, everyone is switching to mobile technology due to popularity of smart phones or we can say that $80 \%$ already have switched to mobile technology. On daily basis number of mobiles are sales all over the world which means that each day passing, more and more people are subscribing to wireless services. Which in return effect the spectrum bandwidth. As result, demand for additional spectral bandwidth is multiplied from current usage.

Here the problem arises, how we can provide the required spectral bandwidth which fulfill the present and future needs for wireless services and wireless applications.

Initially global mobile network face a wireless bandwidth crisis. We can illustrate this problem by the help of cognitive radio. Cognitive Radio can be defined as a system which have ability to sense coexist radio system and recognize its context. So that it can be able to adjust radio system operating parameters autonomously and dynamically. Mobile devices are allowed to only certain frequencies because of which mobile frequencies are crowded. Large crowd may over load the current capacity of spectrum. There is a possibility that local network can get overloaded with current spectrum usage limitation because capacity is not enough for the user.

CR and Dynamic Spectrum Access are encouraging techniques that increase efficiency of spectral bandwidth utilization.

Using cognitive radio technology, we can use any channel or all available frequencies even those that are dedicated to satellite or TV. $\mathrm{CR}$ can understand the language of any radio which in turn enables new levels of interaction. Intelligent devices are capable of communicating with other devices so that whole radio spectrum can be used in most optimal and efficient manner[1].

In this way, we can double or even multiply network speed. CR ensures that you are connected to network, it quickly adapt new situation for the proper operation of network. We can conclude from above discussion that cognitive radio is another efficient and beneficial way of communicating wireless devices. Device transceivers can detect intelligently that which communication channels are vacant or free and which are 
occupied by devices so that it can moves into vacant channels, avoiding occupied channels. Which in return ensure the optimized use of Radio Frequency (RF) while reduces the inference of other users.

$\mathrm{CR}$ in its basic form is the hybrid technology that involves SDR (Software Defined Radio) as it is applicable to spread spectrum communication [2].

\section{COGNITIVE RADIO}

We can describe the term cognitive radio as a system which have ability of sensing and recognizing its context of use, so that it can adjust radio operating parameter. Cognitive radio is wireless communication technology in which devices such as transmitter or receiver can detect which communication channels are not in use and which can be moved to unused channels and which are in use [3].

Cognitive Radio is wireless technology in which transceiver can identify which communication channels are not in use and switch to empty channels accordingly avoiding busy channels. We can utilize spectrum more efficiently $b$ allowing secondary user to use a licensed band in the absence of primary user. Here spectrum hole detection is more important. Spectrum hole corresponds to the opportunities which are existing but yet not developed for safe use of spectrum [4].

Properly selecting the sensed channel according to their availability is the key feature or idea of Cognitive Radio. Cognitive radio are classified and characterized according to the capabilities of cognitive radio enabling them in detecting the availability of channel in the wireless spectrum while sensing the environment of spectrum, which in return enables to change reception parameters and their transmission [7].

\section{Cognitive Radio Functions:}

Cognitive Radio have four major functions. These functions are: i) Spectrum Sensing, ii) Spectrum Management, iii) Spectrum Mobility iv) Spectrum Sharing.

\section{i) Spectrum Sensing:}

Spectrum sensing is able to detect those holes, which are capable of providing high spectral resolution. Spectrum sensing techniques is divided into three categories that are: Transmitter detection, Cooperative detection and Inference base detection.

\section{ii) Spectrum Management:}

Spectrum management is the more important function of cognitive radio because it recognizes the available spectrum, which is best according to the user's communication requirement. It selects the best spectrum band that meets the QoS requirements from all available spectrum bands.

\section{iii) Spectrum Mobility:}

Spectrum mobility is a process in which cognitive radio user can change its frequency of operation according to the need or requirement because cognitive radio network aims to use spectrum dynamically.

\section{iv) Spectrum Sharing:}

Spectrum sharing function provides the best spectrum scheduling method [2].

Cognitive Radio make the transceiver capable to determine geographic location, authorize and identify users, decrypt or encrypt signals, sense those wireless devices which are in operation and adjust the modulation characteristics and output power.

\section{DYNAMIC SPECTRUMACCESS}

Dynamic Spectrum Access technique is used by cognitive radio system to adapt available spectrum holes dynamically even in response of changing circumstances [2].

In other words dynamic spectrum access is basically used to identify spectrum holes and use them to communicate. Dynamic Spectrum Access have three functions. These functions are:
i) Spectrum Awareness
ii) Cognitive Processing
iii) Spectrum Access

\section{i) Spectrum Awareness:}

Spectrum awareness acknowledge the cognitive radio frequency environment whenever ever spectrum access allows you to use available spectrum. So that, it can be used efficiently.

\section{ii) Cognitive Processing:}

It is decision making function that intelligently perform many subtasks to access 
spectrum efficiently. So that, user communication request ca be fulfilled.

\section{iii) Spectrum Access:}

Spectrum access function allows to access spectrum after cognitive processing [5].

\section{M E T H O D O F D Y N A M I C SPECTRUMACCESS}

We have discussed method of dynamic spectrum access and its features in this section which we will use to illustrate cognitive radio and dynamic spectrum access.

Fuzzy logic-based system: Fuzzy logic is a technique that is used when the target problem is complex enough and difficult to model using traditional mathematical methods but can be understand by human being easily. It is artificially intelligent as human being. Fuzzy logic bear a resemblance of human thinking while making decision and satisfy the demand of multidimensional decision making [6].

Fuzzy logic uses set of indirect rules and membership functions to get the desired objective. Fuzzy logic control system using three parts which are given below

I) Fuzzifier,

ii) Fuzzy logic processor

iii) De-fuzzifier [2].

\section{ALGORIITHM USING FUZZY LOGIC SYSTEM FOR COGNITIVE RADIO AND DYNAMIC SPECTRUM ACCESS:}

Mamdani Model: Fuzzy type mamdani inference model and mostly seen and used in fuzzy methodology. With help of mamdani fuzzy model and theory of fuzzy set the first control system was built. It is defined as the toolbox and the output of member functions is expected to be fuzzy sets[8].

This modified design algorithm is used to design the cognitive radio technology. Following is the proposed fuzzy system for CR and dynamic spectrum access using mamdani model.

Figure 1 shows selection of the FIS editor, two inputs and two outputs, Radio, Satellite, Power and Modulation respectively.

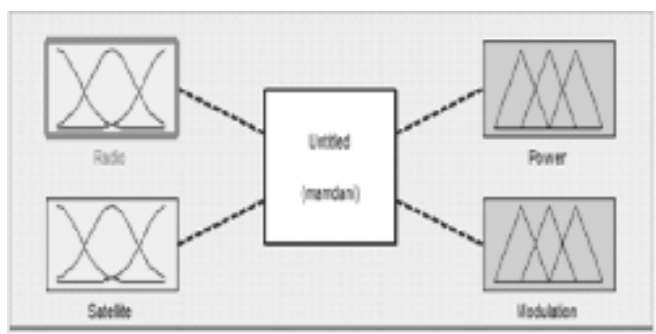

Figure 1. Fuzzy logic system for cognitive radio.

\section{MEMEBERSHIP FUNCTIONS OF INPUT}

Figure 2 shows the membership function editor for the input variable radio frequency.

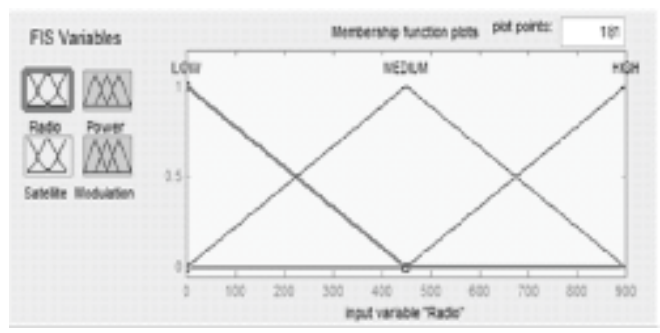

Figure 2. Input variable radio frequency

Figure 3 shows the membership function editor for the input variable satellite frequency.

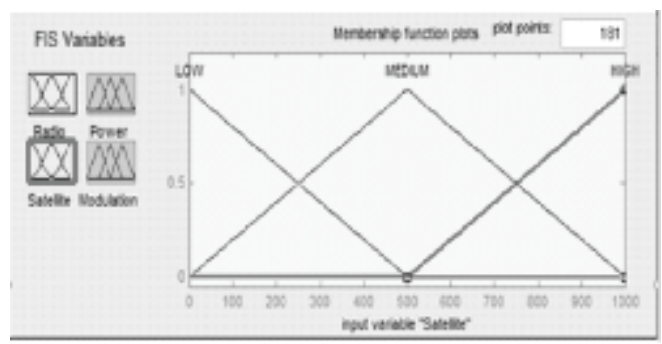

Figure 3. Input variable satellite Frequency

Table 1. Frequency ranges of inputs

\begin{tabular}{|l|l|l|}
\hline Name & $\begin{array}{l}\text { Radio } \\
\text { (Freq) }\end{array}$ & $\begin{array}{l}\text { Satellite } \\
\text { (Freq) }\end{array}$ \\
\hline Low & $0-450$ & $0-250$ \\
\hline Medium & $0-500$ & $0-500$ \\
\hline High & $500-900$ & $500-1000$ \\
\hline
\end{tabular}

Total frequency of radio: $0-900$

Total frequency of satellite: $0-1000$ 


\section{MEMBERSHIP FUNCTIONS OF OUTPUTS}

Figure 4 shows the membership function editor for the output variable Power

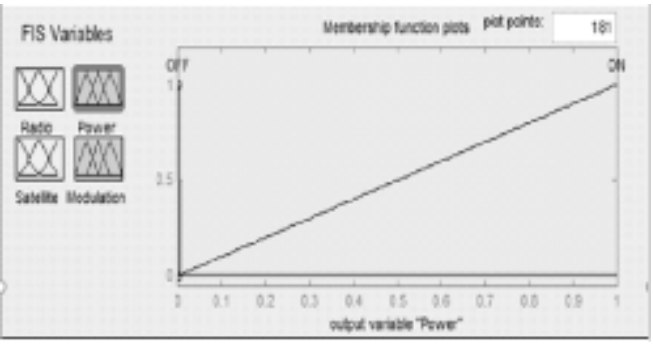

Figure 4. Output variable: Power

Figure 5 shows the membership function editor for the output variable Modulation.

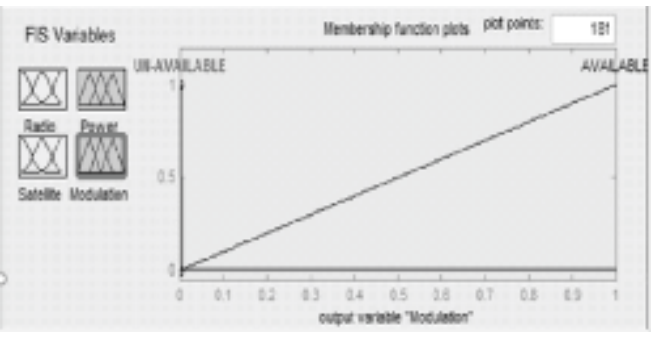

Figure 5. Output variable: Modulation

Table 2. Outputs

\begin{tabular}{|l|l|l|}
\hline Range & Power & Modulation \\
\hline 0 & ON & Unavailable \\
\hline 1 & OFF & Available \\
\hline
\end{tabular}

\section{RULE SLECTOR}

Figure 6 shows the rule selector for the fuzzy logic used for the simulation and finding outputs corresponding to the inputs.
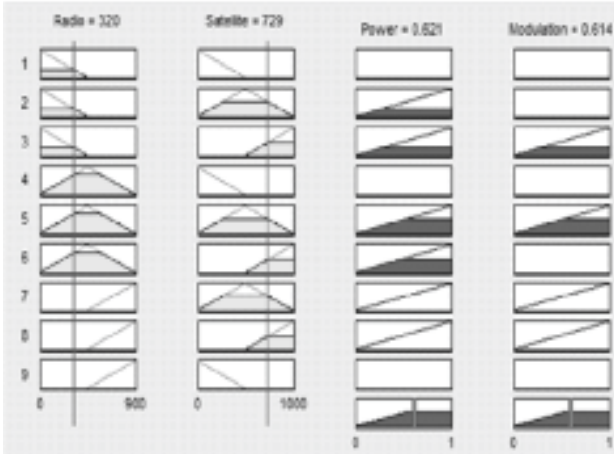

Figure 6. Rule viewer

\section{SURFACE VIEWVER (3D GRAPH)}

Figure 7 shows the 3D graph between inputs: radio and satellite and output: power using the surface viewer.

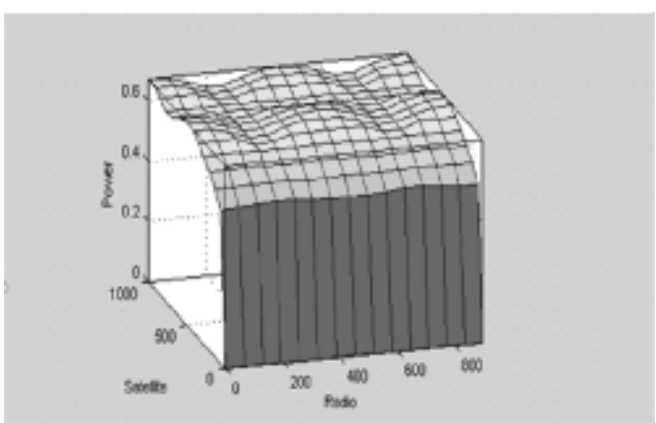

Figure 7. input: radio \& satellite frequency and output: power

Figure 8 shows the 3D graph between inputs: radio and satellite and output: modulation using surface viewer

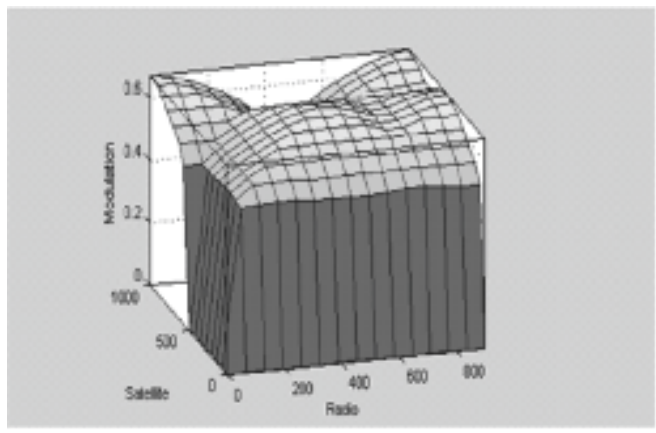

Figure 8. input: radio \& satellite frequency and output: modulation

\section{SURFACE VIEWER (2D GRAPH)}

Figure 9 shows the 2D graph between input: radio and output: modulation using the surface viewer.

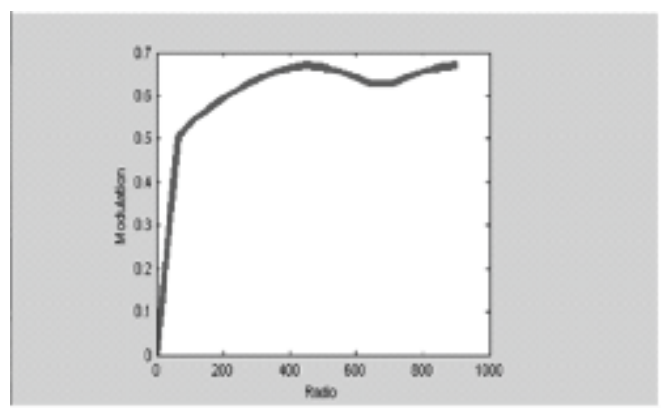

Figure 9. Input: radio \& output: modulation

LGU Research Jounral for Computer Sciences \& IT 3(2) LGURJCSIT 
Figure 10 shows the 2D graph between input: radio and output: power using the surface viewer.

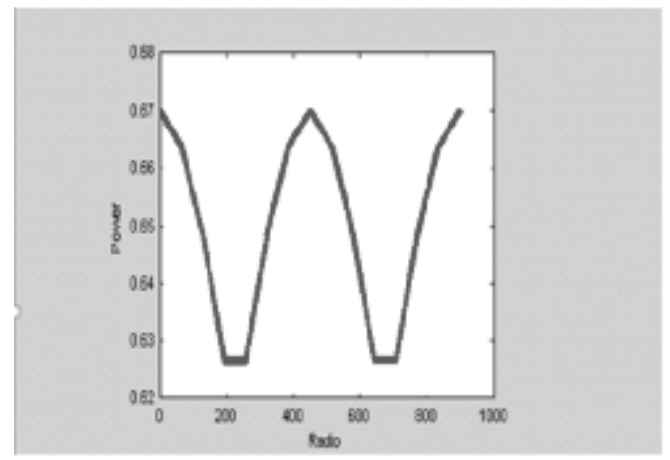

Figure 10. Input: radio \& output: power

Figure 11 shows the 2D graph between input: satellite and output: modulation using the surface viewer.

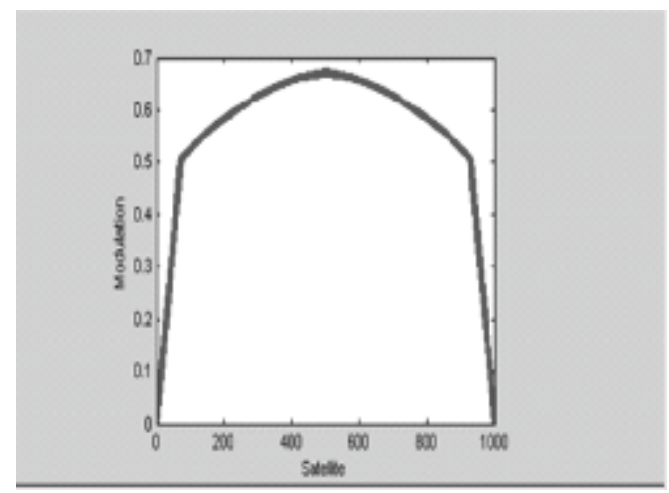

Figure 11. Input: satellite \& output: modulation

\section{CONCULSION}

Cognitive Radio is emerging technology which provide reliable and fastest wireless communication service by using current spectrum band efficiently. System that uses fuzzy logic technique for spectrum management to make decision intelligently about spectrum sharing in cognitive radio network.

In this paper we have presented about cognitive radio and dynamic spectrum access techniques and features. The proposed system is based on fuzzy logic. Fuzzy logic provides the efficient spectrum sensing so that existing spectrum can become more flexible.

\section{REFRENCES}

[1] Anusha, S. and V. Mohanraj, Dynamic spectrum access in cognitive radio wireless sensor networks using different spectrum sensing techniques. International Journal of Applied Engineering Research, 2016. 11(6): p. 4044-4048.

[2] Kose, U., G.E. Guraksin, and O. Deperlioglu, Cognitive development optimization algorithm based support vector machines for determining diabetes. BRAIN. Broad Research in Artificial Intelligence and Neuroscience, 2016. 7(1): p. 80-90.

[3] Benmammar, B., A. Amraoui, and F. Krief, A survey on dynamic spectrum access techniques in cognitive radio networks. International Journal of Communication Networks and Information Security, 2013. 5(2): p. 68 .

[4] Yadav, P., A Survey on Dynamic Spectrum Access Techniques in Cognitive Radio. International Journal of Next-Generation Networks, 2012.4(4): p. 27-46.

[5] Ghosh, G., P. Das, and S. Chatterjee, A Cognitive Radio And Dynamic Spectrum Access - A Study. International Journal of NextGeneration Networks, 2014. 6(1): p. 43-60.

[6] Matinmikko, M., et al., Application of Fuzzy Logic to Cognitive Radio Systems. IEICE Transactions on Communications, 2009. E92B(12):p. 3572-3580.

[7] Arnous, R., El-Desouky, A. I., Sarhan, A., \& Badawy, M. (2018). ILFCS: an intelligent learning fuzzy-based channel selection framework for cognitive radio networks. EURASIP Journal on Wireless Communications and Networking, 2018(1). doi: 10.1186/s13638018-1265-4

[8] Mamdani, E.H. and S. Assilian, "An experiment in linguistic synthesis with a fuzzy logic controller," International Journal of ManMachine Studies, Vol. 7, No. 1, pp. 1-13, 1975. 